\title{
DOPA Decarboxylase Activity in Attention Deficit Hyperactivity Disorder Adults. A [Fluorine-18]Fluorodopa Positron Emission Tomographic Study
}

\author{
Monique Ernst, Alan J. Zametkin, John A. Matochik, Peter H. Jons, and Robert M. Cohen \\ Laboratory of Cerebral Metabolism, National Institute of Mental Health, Bethesda, Maryland 20892
}

Converging evidence implicates the dopaminergic system and the prefrontal and nigrostriatal regions in the pathophysiology of attention deficit hyperactivity disorder (ADHD). Using positron emission tomography (PET) with [fluorine-18]fluorodopa (F18DOPA), we compared the integrity of the presynaptic dopaminergic function between 17 ADHD adults and 23 healthy controls. The ratio of the isotope concentration of specific regions to that of nonspecific regions reflects DOPA decarboxylase activity and dopamine storage processes. Of three composite regions (prefrontal cortex, striatum, and midbrain), only the prefrontal cortex showed significantly different F18-DOPA ratios in ADHD as compared with control adults $(p<0.01)$. The medial and left prefrontal areas were the most altered (lower F18-DOPA ratios by 52 and $51 \%$ in ADHD as compared with controls). Similarly, the interaction [sex $\times$ diagnosis] was sig- nificant only in the prefrontal cortex $(p<0.02)$ : lower ratios in men than in women in ADHD and vice versa in controls. These findings suggest that a prefrontal dopaminergic dysfunction mediates ADHD symptoms in adults and that gender influences this abnormality. On the basis of previous neuroimaging findings in ADHD showing discrepant findings in adults and adolescents and on evidence for midbrain dopaminergic defect in adolescents, we hypothesize that the prefrontal dopaminergic abnormality in ADHD adults is secondary and results from an interaction of the primary subcortical dopaminergic deficit with processes of neural maturation and neural adaptation.

Key words: prefrontal cortex; nigrostriatal pathways; presynaptic dopaminergic function; attention deficit hyperactivity disorder; gender; neurodevelopment; PET; (F18)fluorodopa
Attention deficit hyperactivity disorder (ADHD), a highly prevalent neurodevelopmental disorder, has been ascribed to prefrontal (Mattes, 1980; Benton, 1991; Heilman et al., 1991) and striatonigral dysfunction (Castellanos, 1997; Ernst, 1998). These assumptions are based primarily on the nature of ADHD symptoms, i.e., impaired executive function (Denckla, 1994) and excessive motor activity, traditionally associated with damage in the frontal lobes (Clark et al., 1986; Goldman-Rakic, 1992) and basal ganglia (Graybiel, 1991), respectively. The time course of ADHD (childhood onset and variable outcome into adulthood) and its gender distribution (approximately four boys to one girl) (Barkley, 1996) implicate neural maturation, adaptive neural changes, and sexual genetic or hormonal influences on the frontalstriatal-thalamic network. This network, organized into parallel, segregated circuits (Alexander et al., 1986; DeLong et al., 1990), is modulated mainly by dopamine. Although dysfunction in these areas and associated circuits is proposed as the cause of ADHD, the exact pathophysiological mechanism remains unclear.

Up to $60 \%$ of children with ADHD continue to present impairing symptoms in adulthood (Gittelman et al., 1985; Weiss and Hechtman, 1986; Barkley, 1990). Although recent, the recognition of this disorder later in life has gained considerable importance, notably because of the high rate of comorbidity with

Received March 2, 1998; revised May 7, 1998; accepted May 13, 1998.

We thank the PET technologists and Chemistry Department of Nuclear Medicine, National Institutes of Health Clinical Center, for their assistance in performing this study.

Correspondence should be addressed to Dr. Monique Ernst or Dr. Robert Cohen, National Institutes of Health, Building 36, Room 1A05, 36 Convent Drive, MSC 4030, Bethesda, MD 20892-4030.

Copyright (ㄷ) 1998 Society for Neuroscience $\quad 0270-6474 / 98 / 185901-07 \$ 05.00 / 0$ antisocial personality disorder and substance abuse disorder (Downey et al., 1997; Bellak and Black, 1992; Mannuzza et al., 1993), which worsen severity and outcome. Although stimulant treatment appears as effective in adults as in children (Matochik et al., 1994; Spencer et al., 1995; Wilens et al., 1995), substance abuse liability is a concern. A better understanding of the pathophysiology of this disorder is needed for the development of highly specific therapeutic pharmacological agents. Furthermore, the investigation of ADHD may further our understanding of those neural systems, particularly dopamine, that subserve the cognitive and social behavior that are altered in this disorder.

Converging evidence from genetic and neuroimaging studies has supported the dopaminergic hypothesis of ADHD. Most exciting are the reports of linkages between ADHD and genetic markers of dopaminergic genes (Cook et al., 1995; LaHoste et al., 1996; Gill et al., 1997). In addition, abnormal laterality and function have been reported in dopaminergic structures by MRI (Caparulo et al., 1981; Hynd et al., 1993; Aylward et al., 1996; Castellanos et al., 1996) and SPECT/PET (single-photon emission computed tomography/positron emission tomography), respectively (Lou et al., 1989; Zametkin et al., 1990; Lou, 1991; Zametkin et al., 1993; Ernst et al., 1994, 1997a). Although conceptual models of the neuropathophysiology of ADHD have been proposed (Heilman et al., 1991; Castellanos, 1997; Solanto, 1998), no human studies have yet examined directly, in vivo, the function of specific neurochemical systems implicated in this disorder.

We elected to assess the integrity of the dopaminergic presynaptic function in ADHD, using PET with [fluorine-18]fluorodopa ([F18]FDOPA). The tracer [F18]FDOPA, an analog of DOPA, is transported into presynaptic neurons. There, it is converted by the enzyme DOPA decarboxylase to [F18]FDOPA and stored in 


\section{TEMPLATE OF REGIONS OF INTEREST}

\section{FRONTAL}

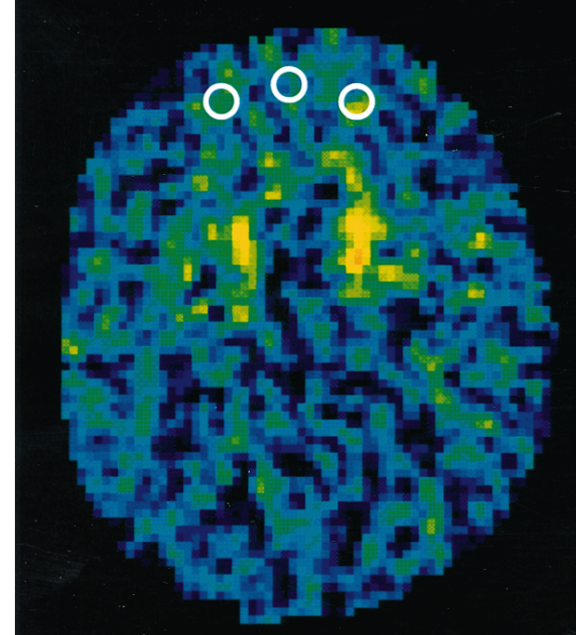

STRIATUM

OCCIPITAL

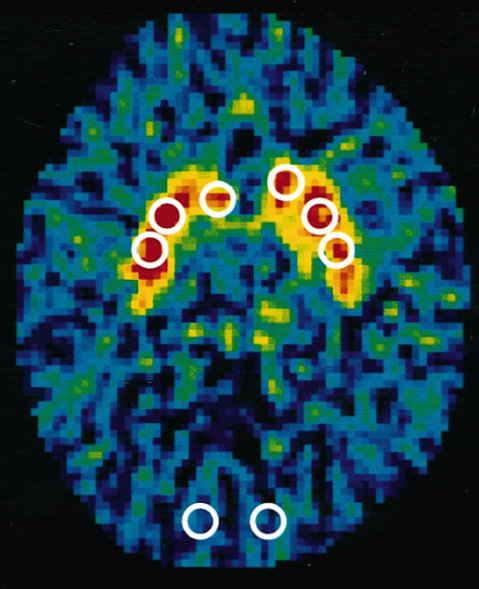

MIDBRAIN

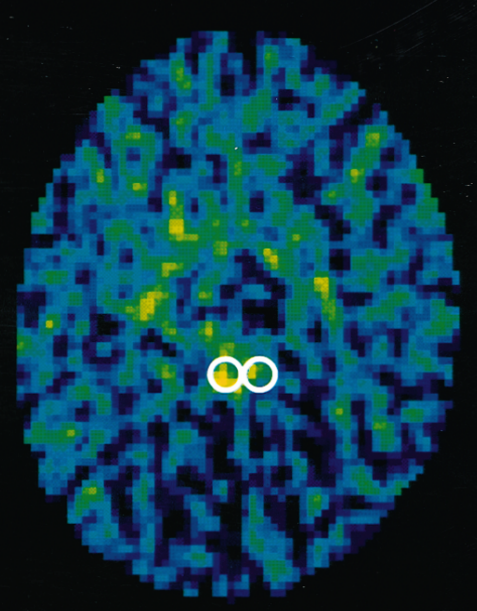

Figure 1. Template of regions of interest (ROIs). The ROIs were placed according to a predetermined algorithm. The slice with the highest striatal FDOPA signal was the "slice of reference" (at approximately the level of the canthomeatal line) and is the one presented in this figure. Striatal ROIs first were placed on the slice of reference and then on both slices directly above and below, respectively. The occipital ROIs were placed on the same slices as those containing the striatal ROIs. The frontal ROIs were placed on the 4th (presented here) and 5th slice above the slice of reference ( $\sim 15-20$ $\mathrm{mm}$ above the striatal plane, at the level of Brodmann area 10). The midbrain ROIs were placed on the 2nd (presented here) and 3rd slice below the slice of reference $(\sim 7$ and $10 \mathrm{~mm}$ below the striatum).

storage vesicles. Therefore, data obtained by using [F18]FDOPA and PET reflect DOPA decarboxylase activity and dopamine storage processes.

\section{MATERIALS AND METHODS}

Subjects. This study was approved by the Human Subjects Protection Committee of the National Institute of Mental Health, and written informed consents were obtained from all subjects after they received a complete description of the study.

Volunteers with ADHD were recruited via advertisement in local newspapers and with the help of an ADHD advocacy and support organization. Screening included a complete physical and laboratory medical work-up. Subjects were evaluated psychiatrically by means of a semi-structured diagnostic interview (Schedule for Affective Disorders and Schizophrenia, life-long version) (Endicott and Spitzer, 1978). Exclusion criteria were any axis I or axis II DSM-III-R psychiatric disorders (American Psychiatric Association, 1987) or any medical problems, in- cluding neurological deficits, history of head trauma with loss of consciousness, and cardiac or blood pressure abnormalities. Behavioral ratings included the 10 item Conners abbreviated teacher's rating scale (Conners-ATRS) (Conners, 1969; Goyette et al., 1978) adapted for adults self-rating. Only four ADHD individuals had a history of treatment with stimulants. None was currently receiving medical treatment. Psychiatric family history in both ADHD and control groups was obtained by structured interviews (Gershon et al., 1988).

Procedures. The study consisted of a 2 hr [F18]FDOPA PET session, including a $90 \mathrm{~min}$ uptake period and a $32 \mathrm{~min}$ acquisition period. The tracer [F18]FDOPA was administered in a $1 \mathrm{~min}$ intravenous infusion at a dose of $5.0 \mathrm{mCi}$. The sensitivity of the method was improved significantly by the following strategy. To increase the availability of [F18]FDOPA in plasma to the brain, we blocked the peripheral decarboxylation of [F18]F DOPA by the administration of $150 \mathrm{mg}$ of carbidopa (L-aromatic amino acid decarboxylase inhibitor) $1 \mathrm{hr}$ before injection of the tracer (McLellan et al., 1991). In addition, to minimize the accumu- 


\begin{tabular}{|c|c|c|c|}
\hline & $\operatorname{ADHD}(n=17)$ & Control $(n=23)$ & $p$ \\
\hline $\operatorname{Sex}(M / F)$ & $8 / 9$ & $13 / 10$ & NS \\
\hline Age & $39.3 \pm 6.2$ & $33.7 \pm 10.5$ & 0.06 \\
\hline Socioeconomic status ${ }^{a}$ & $57.0 \pm 24.5$ & $63.0 \pm 33.5$ & NS \\
\hline Relatives with ADHD & $13 / 17$ & $5 / 17$ & 0.001 \\
\hline History of stimulants & $4 / 17$ & $0 / 23$ & 0.014 \\
\hline History of smoking & $3 / 17$ & $6 / 23$ & NS \\
\hline Utah criteria-past ${ }^{b}$ & $4.94 \pm 0.97$ & $0.05 \pm 0.21$ & 0.000 \\
\hline Utah criteria-present ${ }^{c}$ & $5.41 \pm 1.06$ & $0.09 \pm 0.43$ & 0.000 \\
\hline DSM-III-R past ${ }^{d}$ & $11.6 \pm 2.3$ & $0.75 \pm 1.06$ & 0.000 \\
\hline DSM-III-R present ${ }^{d}$ & $11.0 \pm 2.0$ & $0.75 \pm 1.39$ & 0.000 \\
\hline Conners ATRS ${ }^{e}$ & $15.4 \pm 4.08$ & $2.00 \pm 1.53$ & 0.000 \\
\hline $\mathrm{IQ}^{f}$ & $112.33 \pm 14.3$ & $109.9 \pm 15.2$ & NS \\
\hline
\end{tabular}

$\overline{{ }^{a} \text { SES for socioeconomic status; Hollingshead rating scale (upper-class }=19-31}$; lower-upper class $=32-55$; upper-middle class $=56-86$; lower-middle class $=$ 87-115); scores are based on education and occupation.

${ }^{b}$ Six criteria for childhood history of ADHD.

${ }^{c}$ Seven criteria for the presence of ADHD in adulthood.

${ }^{d}$ Number of DSM-III-R criteria for ADHD (range 0-14) that were met by the subjects (ADHD if $>8$ ).

${ }^{e}$ Conners ATRS: 10-item parents' rating scale for the degree of severity of ADHD; a score $>12$ is consistent with the diagnosis of ADHD.

${ }^{e}$ IQ measured by the WAIS-R.

lation of nonspecific cerebral radioactivity, which originates mostly from the peripheral metabolite 3-O-methyl-6-[F18]FDOPA, we saturated the blood-brain barrier transport system for large neutral amino acids by the intravenous infusion of a solution of unlabeled large neutral amino acids (Travasol 5\%), starting 60 min after injection of the tracer and maintained at a rate of $40 \mathrm{mg} / \mathrm{kg}$ per hour throughout the scanning period (Doudet et al., 1992b). During the first $90 \mathrm{~min}$ of tracer uptake, the subjects were watching a videotape. A custom-fitted plastic head holder was used to immobilize the head during the next $30 \mathrm{~min}$ of scanning time (90-120 min after injection of the tracer).

A seven-slice brain PET (Scanditronix PC-1024-7B, Uppsala, Sweden) was used. The in-plane and axial resolutions were 5.2 and $11.8 \mathrm{~mm}$, respectively. Four transverse levels of seven slices each were collected, i.e., a total of 28 slices, at $3.5 \mathrm{~mm}$ intervals. Transmission scans were used to correct for attenuation at all four transverse levels, using a rotating germanium $\left({ }^{68} \mathrm{Ge}\right)$ pin. Thirty-two circular regions of interest (ROIs) of 37 pixels each (pixel size $=4 \mathrm{~mm}^{2}$ ) were placed onto PET images so as to match a standard template based on the atlas of Matsui and Hirano (1978). The placement of ROIs was performed by a single rater who was unaware of the identity and diagnosis of the subjects. A template of the ROIs reported in this manuscript is provided in Figure 1. A high level of interrater reliability was achieved with this procedure (Semple et al., 1993).

The ratio of specific to nonspecific radioactivity was chosen as the method of analysis. This method has been shown to provide accurate and reliable data and to be sensitive to changes in dopaminergic function (Doudet et al., 1992a; Ernst et al., 1996). Presynaptic accumulation of [F18]fluorodopamine was measured in anatomical ROIs drawn on five brain areas rich in dopamine (four lateralized pairs: head of caudate nucleus, putamen, midbrain, and lateral prefrontal cortex; one medial: medial prefrontal cortex) and one region poor in dopamine (occipital cortex) (Fig. 1). To reduce variability, we measured each regional F-18 signal in two (for the frontal, midbrain, and occipital regions) or three consecutive planes (for the caudate and putamen regions) that included the plane with the highest signal; the mean of these measures was used for analysis. The midbrain region included the mesencephalic dopaminerich cell bodies of the substantia nigra and of the ventral tegmentum. So that the effects of differences in input tracer and measurement errors could be minimized, the [F18] activity from the occipital cortex served as the measure of nonspecific activity and was used to normalize [F18] activity of the dopamine-rich areas. These normalized values or ratios, obtained from the formula [(region of interest [F18] - occipital [F18])/ occipital [F18]], were the variables used for analysis and are referred to as the F18-ratio.

Statistical analysis. Three multivariate ANOVA (MANOVA) tested the interactions and main effects of two between-group factors (diagnosis, sex) and two within-subjects factors (region and side) on the F18ratios of the prefrontal cortex (medial, left, and right prefrontal areas), the striatum (left and right: caudate, anterior putamen, and posterior putamen), and the midbrain (left and right). Statistically significant results were investigated further by Student's $t$ tests.

The potential influences of age and history of smoking on the F18ratios of the composite four regions, prefrontal (medial, and left and right), caudate nucleus (left and right), putamen (left and right), and midbrain (left and right), were tested by analyses of Pearson productmoment correlation coefficients and a MANOVA, respectively. Age was not correlated with F18-ratios in any of the four composite regions in either the ADHD $(0.04<r<0.42 ; n=17 ; 0.09<p<0.87)$ or the control group $(0.11<r<0.38 ; n=23 ; 0.22<p<0.61)$. Similarly, a history of smoking did not influence F18-ratios (diagnosis $\times$ smoking: $F_{(1,35)}=0.01, p=0.94$; smoking: $\left.F_{(1,35)}=0.00, p=0.98\right)$. Thus, age and history of smoking were not controlled for in the analysis of the results.

The association of clinical measures with regional F18-ratios was assessed by means of Pearson product-moment correlation coefficients. Only those measures that significantly differed between groups were entered in the analysis. Clinical measures of severity of ADHD symptoms were the overall scores on the 10 item Conners rating scale, the number of DSM-III-R criteria for ADHD met currently and in childhood, and the number of Utah criteria for ADHD met for past and current symptomatology.

Statistical significance was set at $p<0.05$ and statistical trend at $p<$ 0.10 . All tests were two-tailed.

\section{RESULTS}

Seventeen adults with ADHD ( 8 males and 9 females; $39.3 \pm 6.2$ years old) and 23 control adults (13 males and 10 females; $33.7 \pm$ 10.5 years old) completed the study. Demographic and behavioral characteristics are described in Table 1. Mean age tended to be higher in the ADHD than in the control group $(t=1.94$; $\mathrm{df}=38$; $p=0.06$ ), yet because age did not correlate significantly with the F18-ratios of the four large regions analyzed (frontal, caudate nucleus, putamen, and midbrain), it was not entered as a covariate in subsequent analyses.

Interactions and main effects of diagnosis, laterality, and gender are summarized in Table 2. Diagnosis influenced F18-ratios

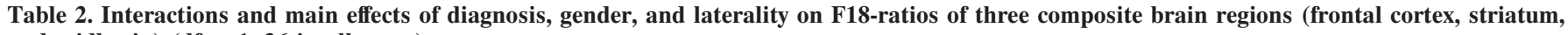
and midbrain) $(\mathrm{df}=1,36$ in all cases $)$

\begin{tabular}{|c|c|c|c|c|c|c|c|c|}
\hline & \multicolumn{2}{|c|}{ Diagnosis $\cdot$ Gender } & \multicolumn{2}{|c|}{ Diagnosis $\cdot$ Laterality } & \multicolumn{2}{|c|}{ Diagnosis } & \multicolumn{2}{|c|}{ Gender } \\
\hline & $F$ & $P$ & $F$ & $P$ & $F$ & $P$ & $F$ & $P$ \\
\hline Prefrontal $^{a}$ & 5.54 & 0.02 & $0.35^{b}$ & 0.56 & 6.72 & 0.01 & 0.51 & 0.48 \\
\hline Striatum $^{a}$ & 2.38 & 0.35 & 0.02 & 0.88 & 0.43 & 0.51 & 3.99 & 0.05 \\
\hline Midbrain $^{b}$ & 0.59 & 0.45 & 2.44 & 0.13 & 0.06 & 0.81 & 0.03 & 0.87 \\
\hline
\end{tabular}

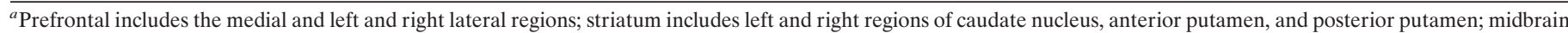
includes left and right midbrain regions.

${ }^{b}$ A separate repeated measures ANOVA for left and right prefrontal without the medial prefrontal region was performed. 


\begin{tabular}{|c|c|c|c|c|}
\hline ROI & ADHD & & Control & \\
\hline \multirow{2}{*}{$\begin{array}{l}\text { Medial } \\
\text { Prefrontal }\end{array}$} & $0.26 \pm 0.26$ & & $0.54 \pm 0.34$ & \\
\hline & Left & Right & Left & Right \\
\hline $\begin{array}{l}\text { Lateral } \\
\text { Prefrontal }\end{array}$ & $0.21 \pm 0.27$ & $0.31 \pm 0.28$ & $0.43 \pm 0.36$ & $0.46 \pm 0.32$ \\
\hline Caudate & $3.54 \pm 0.68$ & $3.62 \pm 0.86$ & $3.55 \pm 0.85$ & $3.59 \pm 0.84$ \\
\hline Putamen & $3.82 \pm 0.71$ & $3.80 \pm 0.65$ & $3.95 \pm 0.80$ & $3.93 \pm 0.79$ \\
\hline Midbrain & $1.29 \pm 0.53$ & $1.14 \pm 0.52$ & $1.24 \pm 0.48$ & $1.27 \pm 0.52$ \\
\hline
\end{tabular}

Mean \pm SD.

F18-ratio $=[$ ROI-Occipital $] /$ Occipital; $(\mathrm{nCi} / \mathrm{cc}, \mathrm{nCi} / \mathrm{cc})$.

\begin{tabular}{|c|c|c|c|c|}
\hline & \multicolumn{2}{|l|}{ ADHD } & \multicolumn{2}{|l|}{ Control } \\
\hline & $\begin{array}{l}\text { Female } \\
(n=9)\end{array}$ & $\begin{array}{l}\text { Male } \\
(n=8)\end{array}$ & $\begin{array}{l}\text { Female } \\
(n=10)\end{array}$ & $\begin{array}{l}\text { Male } \\
(n=13)\end{array}$ \\
\hline Medial prefrontal & $0.27 \pm 0.29$ & $0.24 \pm 0.24$ & $0.44 \pm 0.27$ & $0.61 \pm 0.37$ \\
\hline Left prefrontal & $0.30 \pm 0.31$ & $0.12 \pm 0.20$ & $0.24 \pm 0.32$ & $0.58 \pm 0.33$ \\
\hline Right prefrontal & $0.40 \pm 0.25$ & $0.21 \pm 0.28$ & $0.34 \pm 0.20$ & $0.56 \pm 0.36$ \\
\hline Left caudate & $3.84 \pm 0.69$ & $3.21 \pm 0.54$ & $3.76 \pm 1.09$ & $3.40 \pm 0.61$ \\
\hline Right caudate & $3.98 \pm 0.85$ & $3.22 \pm 0.71$ & $3.76 \pm 1.00$ & $3.47 \pm 0.71$ \\
\hline $\begin{array}{l}\text { Left anterior } \\
\text { putamen }\end{array}$ & $4.17 \pm 0.75$ & $3.43 \pm 0.42$ & $4.04 \pm 0.98$ & $3.89 \pm 0.68$ \\
\hline $\begin{array}{l}\text { Right anterior } \\
\text { putamen }\end{array}$ & $4.09 \pm 0.66$ & $3.50 \pm 0.52$ & $4.11 \pm 0.96$ & $3.80 \pm 0.65$ \\
\hline $\begin{array}{l}\text { Left posterior } \\
\text { putamen }\end{array}$ & $3.51 \pm 0.68$ & $2.91 \pm 0.30$ & $3.40 \pm 0.79$ & $3.39 \pm 0.54$ \\
\hline $\begin{array}{l}\text { Right posterior } \\
\text { putamen }\end{array}$ & $3.28 \pm 0.43$ & $2.82 \pm 0.76$ & $3.42 \pm 0.82$ & $3.20 \pm 0.57$ \\
\hline Left midbrain & $1.37 \pm 0.62$ & $1.21 \pm 0.43$ & $1.23 \pm 0.63$ & $1.25 \pm 0.36$ \\
\hline Right midbrain & $1.21 \pm 0.49$ & $1.07 \pm 0.58$ & $1.18 \pm 0.59$ & $1.35 \pm 0.46$ \\
\hline
\end{tabular}

Mean \pm SD

F18-ratio $=[$ ROI-Occipital $] /$ Occipital; $(\mathrm{nCi} / \mathrm{cc}, \mathrm{nCi} / \mathrm{cc})$.

only in the prefrontal cortex: F18-ratios were lower in ADHD than in controls (see Tables 3 and 4). Post hoc simple comparisons showed that both F18-ratios in the medial and left lateral prefrontal areas were, respectively, 52 and $51 \%$ significantly lower in ADHD than in controls (medial prefrontal: $t=2.90, \mathrm{df}=38, p=$ 0.006; left lateral prefrontal: $t=2.09$, $\mathrm{df}=38, p=0.04$ ) (Figs. 2, 3 ). In addition, the prefrontal cortex was the only region in which the relative male-to-female F18-ratios values were different as a function of diagnosis: in ADHD, F18-ratios were lower in men as compared with women; the opposite was found in controls. Of interest, women had higher striatal F18-ratios than men in both ADHD and control groups. Finally, laterality was not affected by diagnosis in any of the regions sampled.

In the ADHD group the F18-ratios of the medial prefrontal cortex did not correlate with any measures of severity of ADHD, whereas F18-ratios of the left prefrontal cortex were correlated negatively with Utah criteria of childhood ADHD $(r=-0.54$; $n=17 ; p=0.03$ ) (Fig. 4).

\section{DISCUSSION}

Adults with ADHD have abnormally low DOPA decarboxylase activity in the prefrontal cortex, particularly in the medial and left lateral areas.

\section{MEDIAL PREFRONTAL CORTEX}

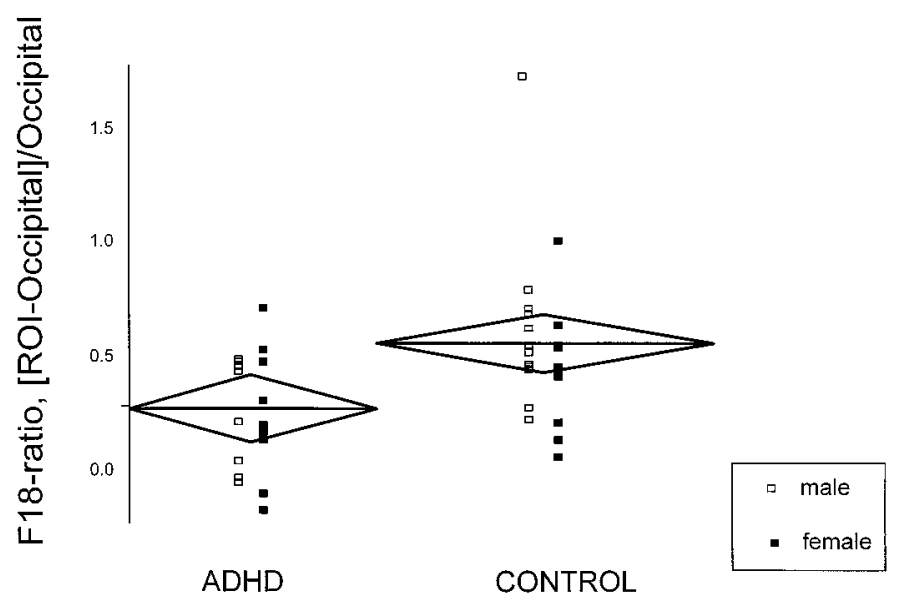

Figure 2. Scatter plot of individual F18-ratio values of the medial prefrontal cortex $(\mathrm{F} 18$-ratio $=[$ ROI-occipital $] /$ occipital; $\mathrm{nCi} / \mathrm{cc}, \mathrm{nCi} / \mathrm{cc})$. The horizontal line in each diamond represents the group mean (for both women and men); its length represents the group size, and its height represents the $95 \%$ confidence interval.

Two caveats need to preamble the discussion of these findings: the variability of the F18-ratios is increased in regions with relatively low dopaminergic neural density (e.g., prefrontal cortex) or of small sizes (e.g., dopaminergic cell body nuclei of the midbrain), which weakens the power to detect significant differences between groups. For example, a mean difference of $33 \%$ in the F18-ratios of the right prefrontal cortex does not reach statistical significance. Furthermore, the frontal signal is not quite dopamine-specific, because it arises from both dopaminergic and noradrenergic nerve terminals. Thus, the involvement of other monoamines and areas cannot be ruled out.

Although not the limiting factor in the rate of dopamine synthesis, DOPA decarboxylase is the limiting step for F-dopamine synthesis from F-DOPA (Gjedde et al., 1991, 1993). Therefore, a lower F18 signal reflects reduction in the activity of the enzyme, either structurally, i.e., decreased number of synapses, or functionally, i.e., inhibition of the enzymatic activity (decreased concentration or affinity). Structurally, a fewer number of synapses would be consistent with a reduction of dopaminergic terminals, which may result from a toxic effect or from an adaptive response to an imbalance in the dopaminergic network. Functionally, the inhibition of the enzyme could reflect deficits in other functional units of the dopaminergic system. Indeed, low extracellular dopamine concentration and blockade of D1 or D2 dopamine receptors have been associated with upregulation of DOPA decarboxylase (Abercrombie et al., 1990; Hadjiconstantinou et al., 1993; Zhu et al., 1993; Torstenson et al., 1997), whereas activation of these receptors has been shown to downregulate DOPA decarboxylase (Hadjiconstantinou et al., 1993; Zhu et al., 1993). The exact mechanism leading to lower DOPA decarboxylase cannot be identified in this study and neither can the role of this abnormality as a primary or secondary effect in ADHD. However, findings from the literature can suggest the most likely mechanisms.

Because clinical and biological findings in ADHD differ between adults and children, we propose that the prefrontal dopaminergic deficits in ADHD adults are not the primary patholog- 


\section{LEFT PREFRONTAL CORTEX}

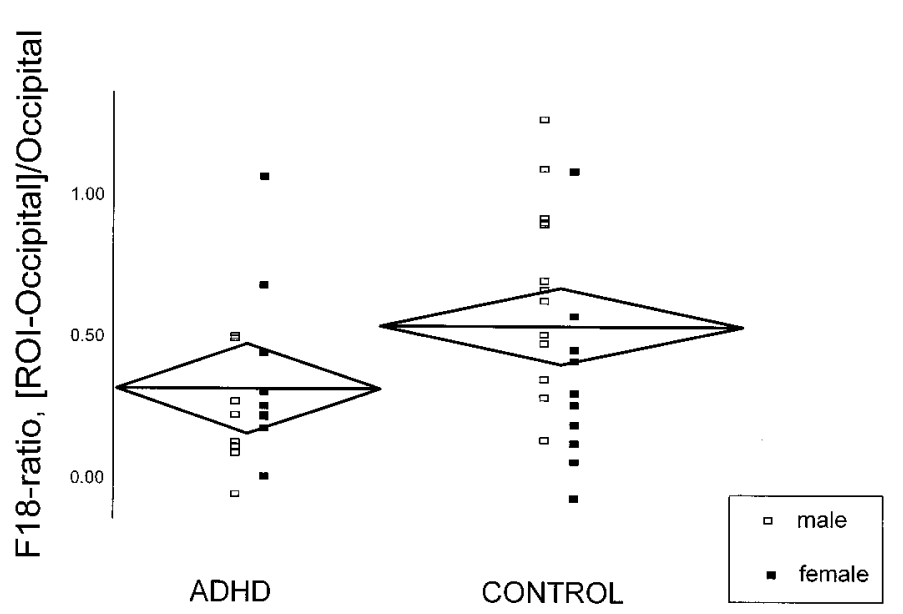

Figure 3. Scatter plot of individual F18-ratio values of the left prefrontal cortex (F18-ratio $=[$ ROI-occipital $] /$ occipital; $\mathrm{nCi} / \mathrm{cc}, \mathrm{nCi} / \mathrm{cc})$. The horizontal line in each diamond represents the group mean (for both women and men); its length represents the group size, and its height represents the $95 \%$ confidence interval.

ical defect but, rather, result from an interaction of the primary neural deficit with maturation and aging processes. Clinically, adults who continue to meet criteria for ADHD present less hyperactivity but unchanged impairment in attention as compared with their childhood symptoms (American Academy of Child and Adolescent Psychiatry, 1997). This clinical evolution suggests that a functional normalization of the structures that control motor activity (mainly basal ganglia) may occur either via compensatory neural mechanisms or a combination of learned and age-related changes.

Consistent with this hypothesis, a functional normalization of subcortical dopaminergic structures has been observed indirectly. CSF or blood concentrations of the dopaminergic metabolite homovanillic acid (HVA) have been found abnormal in ADHD children (Shaywitz et al., 1977; Castellanos et al., 1994), but not in ADHD adults (Reimherr et al., 1984; Ernst et al., 1997b). The primary site of origin for HVA in the CSF has been ascribed to the structures of densest dopaminergic innervation (nigrostriatum) (Amin et al., 1992). Conversely, the failure to detect plasma or CSF dopaminergic aberrations would be expected were the dopaminergic abnormality in ADHD circumscribed to areas receiving moderate dopaminergic input, such as the prefrontal cortex. These findings suggest that the subcortical dopaminergic nuclei are affected in children more than in adults.

Further evidence comes from neuroimaging studies, which have the advantage of directly assessing defined localized areas of structural or functional neurochemical specificity. PET studies of ADHD have revealed different patterns of cerebral metabolic rates of glucose (CMRglc) in adolescents and adults (Zametkin et al., 1990; Ernst et al., 1994). Although abnormally low in adults (Zametkin et al., 1990), global CMRglc was unaltered in adolescents (Zametkin et al., 1993; Ernst et al., 1994). However, when regional CMRglc were normalized (regional/global), the left prefrontal cortex was the region most affected in adults (Zametkin et al., 1990) and adolescents (Ernst et al., 1994). Furthermore, because CMRglc seemed to be more deviant in girls than in boys in a small subsample of 11 girls (Ernst et al., 1994), an indepen-

\section{CORRELATION BETWEEN LEFT PREFRONTAL CORTEX AND UTAH-CRITERIA}

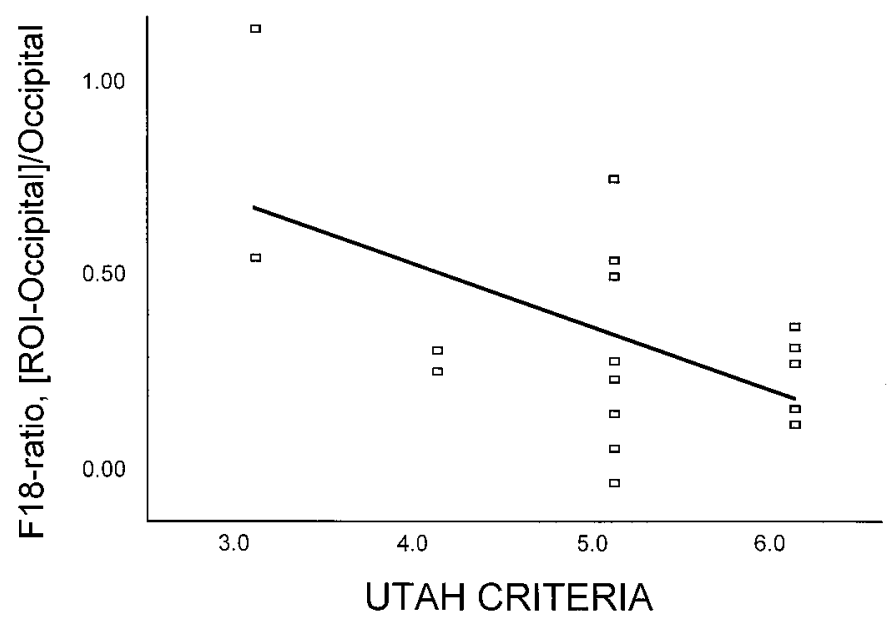

Figure 4. Regression line of F18-ratios of the left prefrontal cortex with the number of Utah criteria met for the presence of ADHD in childhood in the ADHD group.

dent larger sample of 21 girls was studied and revealed dysfunction in the anterior putamen (Ernst et al., 1997a). Taken together, these neuroimaging data suggest a more extensive cortical involvement in ADHD adults than in ADHD adolescents.

The findings of different patterns of abnormalities in ADHD girls than in ADHD boys need to be assessed more carefully with larger samples, yet the role of the putamen in ADHD girls is consistent with hypotheses of nigrostriatal dysf unction (Castellanos, 1997; Ernst, 1998). The gender-related difference seems to hold true for both adolescents and adults. However, whereas girls may have CMRglc more deviant than boys, women seem to show less dopaminergic dysfunction than men (lower F18-ratios in ADHD men than in ADHD women). The protective effect of estrogen on the dopaminergic system (Thompson and Moss, 1997) and the physiological dopamine loss with age (Roth and Joseph, 1994) will need to be considered in the working model of the pathophysiology of ADHD.

Finally, our laboratory recently completed a study of PET and [F18]FDOPA comparing 10 ADHD adolescents with 10 agematched controls (our unpublished data) and found a significantly higher F18-ratio of the right midbrain in the ADHD group than in the control group. Although lower by $15 \%$ in ADHD, F18ratios in the medial prefrontal cortex did not differ significantly between ADHD and control adolescents. The discrepancy between the adult and the adolescent [F18]FDOPA findings may have reflected the inadvertent selection of two different populations. For example, the adolescents may not continue to present ADHD symptoms in adulthood, whereas the adults have a form of ADHD that remains into adulthood. This hypothesis based on the heterogeneity of ADHD may be of use for genetic studies. The reports of an association between the seven-repeat allele of D4 gene and ADHD (LaHoste et al., 1996) may be a better marker for the type of ADHD that continues into adulthood, 
because this dopamine receptor is found in the frontal cortex, but not in the nigrostriatum, in humans (Matsumoto et al., 1995). The association of ADHD with markers of the dopamine transporter gene (Cook et al., 1995; Gill et al., 1997) may be more central to the initial functional deficit that seems to involve the dopaminergic nuclei where dopamine transporters are highly concentrated.

Another hypothesis involves the developmental trajectory of the neural substrates of ADHD. Dopamine has been shown to play an important role in neurogenesis (Schmidt et al., 1996; Levitt et al., 1997), and an early disruption of the dopamine system is likely to affect brain maturation. Significant brain maturational changes occur during adolescence; notwithstanding, the age-related decline of dopaminergic innervation seems to be steepest between 10 and 20 years of age (Seeman et al., 1987). In addition, although based on a limited number of adolescents studied $(n=3)$, cortical and subcortical synaptic activity indexed by PET assay of CMRglc was reported to plateau in early adolescence (10-15 years) before decreasing to adult levels (Chugani et al., 1987). Parallel to these maturational changes that reflect neuronal pruning (Changeux and Danchin, 1976; Huttenlocher, 1979; Cowan et al., 1984; Bourgeois et al., 1994), a functionally specific refinement of the prefrontal neural circuitry has been demonstrated in nonhuman primates during the peripubertal period (Woo et al., 1997). This reorganization affects the superficial layers of the prefrontal cortex where the density of dopamine axons is the greatest (Lewis et al., 1998). Because developmentally the density of dopaminergic synapses appears to peak before this peripubertal reorganization (Lewis et al., 1998), dopamine is likely to influence this neural maturation. With respect to ADHD, these maturational changes may contribute to the shift of the dopaminergic abnormality from midbrain in children to prefrontal cortex in adults; synaptic pruning in the basal ganglia may compensate for the increased presynaptic level of DOPA decarboxylase in midbrain of ADHD children and unmask functional dopaminergic deficit in the prefrontal cortex of ADHD adults. Alternatively, the reduction in dopamine function in the prefrontal cortex may serve to compensate for the dopaminergic abnormality in midbrain. Deafferentation of prefrontal dopamine projections has been shown to upregulate dopamine function in the basal ganglia (Pycock et al., 1980; King and Finlay, 1995). It is also possible that the prefrontal dopaminergic deficit is secondary to a neurotoxic effect of dopamine (Alagarsamy et al., 1997) that could be released in abnormal concentrations in the prefrontal terminal field because of subcortical dopaminergic dysregulation.

In conclusion, the present work sets the direction for the investigation of the neural mechanisms that mediate ADHD. Future studies need to examine systematically each of the functional units of the dopamine system to identify the exact nature of the dopaminergic dysfunction in ADHD. Furthermore, research in ADHD is ripe for combining both brain imaging and genetics approaches. Proposed strategies include the examination of the effects of susceptibility genes on neuroimaging findings and, reciprocally, the exploitation of homogenous brain imaging phenotypes in the search of candidate genes.

\section{REFERENCES}

Abercrombie ED, Bonatz AE, Zigmond MJ (1990) Effects of L-dopa on extracellular dopamine in striatum of normal and 6-hydroxydopaminetreated rats. Brain Res 525:36-44.

Alagarsamy S, Phillips M, Pappas T, Johnson KM (1997) Dopamine neurotoxicity in cortical neurons. Drug Alcohol Depend 48:105-111.

Alexander GE, DeLong MR, Strick PL (1986) Parallel organization of functionally segregated circuits linking basal ganglia and cortex. Annu Rev Neurosci 9:357-381.

American Academy of Child and Adolescent Psychiatry (1997) Practice parameters for the assessment and treatment of children, adolescents, and adults with attention-deficit/hyperactivity disorder. J Am Acad Child Adolesc Psychiatry 36:85S-121S.

American Psychiatric Association (1987) Diagnostic and statistical manual of mental disorders (DSM-III-R), 3rd ed, Revised. Washington, DC: American Psychiatric Association.

Amin F, Davidson M, Davis KL (1992) Homovanillic acid measurement in clinical research: a review of methodology. Schizophr Bull 18:123-148.

Aylward EH, Reiss AL, Reader MJ (1996) Basal ganglia volumes in children with attention-deficit hyperactivity disorder. J Child Neurol 11:112-115.

Barkley R (1990) Developmental course and adult outcome. In: Attention deficit hyperactivity disorder. A handbook for diagnosis and treatment, pp 114-129. New York: Guilford.

Barkley RA (1996) Attention-deficit hyperactivity disorder. In: Child psychopathology (Mash EJ, Barkley RA, eds), pp 63-112. New York: Guilford.

Bellak L, Black RB (1992) Attention-deficit hyperactivity disorder in adults. Clin Ther 14:138-147.

Benton A (1991) Prefrontal injury and behavior in children. Dev Neuropsychol 7:275-282.

Bourgeois JP, Goldman-Rakic PS, Rakic P (1994) Synaptogenesis in the prefrontal cortex of rhesus monkeys. Cereb Cortex 4:78-96.

Caparulo BK, Cohen DJ, Rothman SL, Young JG, Katz JD, Shaywitz SE, Shaywitz BA (1981) Computed tomographic brain scanning in children with developmental neuropsychiatric disorders. J Am Acad Child Adolesc Psychiatry 20:338-357.

Castellanos FX (1997) Toward a pathophysiology of attention-deficit hyperactivity disorder. Clin Pediatr (Phila) 36:381-393.

Castellanos FX, Elia J, Kruesi MJP, Gulotta CS, Mefford IN, Potter WZ, Ritchie GF, Rapoport JL (1994) Cerebrospinal fluid monoamine metabolites in boys with attention deficit hyperactivity disorder. Psychiatry Res 52:305-316.

Castellanos FX, Giedd JN, Marsh WL (1996) Quantitative brain magnetic resonance imaging in attention-deficit/hyperactivity disorder. Arch Gen Psychiatry 53:607-616.

Changeux JP, Danchin A (1976) Selective stabilization of developing synapses as a mechanism for the specification of neuronal networks. Nature 264:705-712.

Chugani HT, Phelps ME, Mazziotta JC (1987) Positron emission tomography study of human brain functional development. Ann Neurol 22:487-497.

Clark CR, Geffen GM, Geffen LB (1986) Role of monoamine pathways in the control of attention: effects of droperidol and methylphenidate in normal adult humans. Psychopharmacology 90:28-34.

Conners CK (1969) A teacher rating scale for use in drug studies with children. Am J Psychiatry 126:884-888.

Cook EH, Stein MA, Krasowski MD (1995) Association of attention deficit disorder and the dopamine transporter gene. Am J Hum Genet 56:993-998.

Cowan WM, Fawcett JW, O'Leary DD, Stanfield BB (1984) Regressive events in neurogenesis. Science 225:1258-1265.

DeLong MR, Alexander GE, Miller WC, Crutcher MD (1990) Anatomical and functional aspects of basal ganglia-thalamocortical circuits. In: Function and dysfunction in the basal ganglia (Franks AJ, Ironside JW, Mindham RHS, Smith RJ, Spokes EGS, Winlow W, eds), pp 3-32. Manchester, UK: Manchester UP.

Denckla MB (1994) Measurement of executive function. In: Frames of reference for the assessment of learning disabilities: new views on measurement issues (Lyon GR, ed), pp 117-142. Baltimore: Brookes.

Doudet DJ, Aigner TG, McLellan CA, Cohen RM (1992a) Positron emission tomography with 18-F-dopa: interpretation and biological correlates in non-human primates. Psychiatry Res 45:153-168.

Doudet DJ, McLellan CA, Aigner TG, Wyatt RJ, Cohen RM (1992b) Delayed L-phenylalanine infusion allows for simultaneous kinetic analysis and improved evaluation of specific-to-nonspecific fluorine-18-dopa uptake in brain. J Nucl Med 33:1383-1389.

Downey KK, Stelson FW, Pomerleau OF, Giordani B (1997) Adult attention deficit hyperactivity disorder: psychological test profiles in a clinical population. J Nerv Ment Dis 185:32-38.

Endicott J, Spitzer RL (1978) A diagnostic interview: the schedule for 
affective disorders and schizophrenia. Arch Gen Psychiatry 35:837-844.

Ernst M (1998) Dopaminergic function in ADHD. In: Dopaminergic disorders: novel approaches for drug discovery and development, pp 235-260. Southborough, MA: IBC.

Ernst M, Liebenauer LL, King AC, Fitzgerald GA, Cohen RM, Zametkin AJ (1994) Reduced brain metabolism in hyperactive girls. J Am Acad Child Adolesc Psychiatry 33:858-868.

Ernst M, Zametkin A, Matochik J, Pascualvaca D, Jons P, Hardy K, Hankerson J, Doudet D, Cohen R (1996) Presynaptic dopaminergic deficits in Lesch-Nyhan disease. N Engl J Med 334:1568-1604.

Ernst M, Cohen RM, Liebenauer LL, Jons PH, Zametkin AJ (1997a) Cerebral glucose metabolism in adolescent girls with attention-deficit/ hyperactivity disorder. J Am Acad Child Adolesc Psychiatry 36:1399-1406.

Ernst M, Liebenauer LL, Tebeka D, Jons PH, Eisenhofer G, Murphy DL, Zametkin AJ (1997b) Selegiline in ADHD adults. II. Plasma monoamines and monoamine metabolite. Neuropsychopharmacology $16: 276-284$.

Gershon ES, DeLisi LE, Hamovit J, Nurnberger JIJ, Maxell ME, Schreiber J, Dauphinais D, Dingman CWI, Guroff JJ (1988) A controlled family study of chronic psychosis. Arch Gen Psychiatry 45:328-336.

Gill M, Daly G, Heron S, Hawi Z, Fitzgerald M (1997) Confirmation of association between attention deficit hyperactivity disorder and a dopamine transporter polymorphism. Mol Psychiatry 2:311-313.

Gittelman R, Mannuzza S, Shenker R, Bonagura N (1985) Hyperactive boys almost grown up. I. Psychiatric status. Arch Gen Psychiatry 42:937-947.

Gjedde A, Reith J, Dyve S, Léger G, Guttman M, Diksic M, Evans A, Kuwabara H (1991) Dopa decarboxylase activity of the living human brain. Proc Natl Acad Sci USA 88:2721-2725.

Gjedde A, Léger GC, Cumming P, Yasuhara Y, Evans AC, Guttman M, Kuwabara H (1993) Striatal L-dopa decarboxylase activity in Parkinson's disease in vivo: implications for the regulation of dopamine synthesis. J Neurochem 61:1538-1541.

Goldman-Rakic PS (1992) Dopamine-mediated mechanisms of the prefrontal cortex. Semin Neurosci 4:149-159.

Goyette CH, Conners CK, Ulrich RF (1978) Normative data on revised Conners parent and teacher rating scales. J Abnorm Child Psychol 6:221-236.

Graybiel AM (1991) Basal ganglia-input, neural activity, and relation to the cortex. Curr Opin Neurobiol 1:644-651.

Hadjiconstantinou M, Wemlinger TA, Sylvia CP, Hubble JP, Neff NH (1993) Aromatic L-amino acid decarboxylase activity of mouse striatum is modulated via dopamine receptors. J Neurochem 60:2175-2180.

Heilman KM, Voeller KKS, Nadeau SE (1991) A possible pathophysiologic substrate of attention deficit hyperactivity disorder. J Child Neurol 6:S76-S81.

Huttenlocher PR (1979) Synaptic density in human frontal cortex-developmental changes and effects of aging. Brain Res 163:195-205.

Hynd GW, Hern KL, Novey ES (1993) Attention deficit hyperactivity disorder and asymmetry of the caudate nucleus. J Child Neurol 8:339-347.

King D, Finlay J (1995) Effects of selective dopamine depletion in medial prefrontal cortex on basal and evoked extracellular dopamine in neostriatum. Brain Res 685:117-128.

LaHoste GJ, Swanson JM, Wigal SB (1996) Dopamine D4 receptor gene polymorphisms associated with attention deficit hyperactivity disorder. Mol Psychiatry 1:121-124.

Levitt P, Harvey JA, Friedman E, Simansky K, Murphy EH (1997) New evidence for neurotransmitter influences on brain development. Trends Neurosci 20:269-274.

Lewis DA, Sesack SR, Levey AI, Rosenberg DR (1998) Dopamine axons in primate prefrontal cortex: specificity of distribution, synaptic targets, and development. Adv Pharmacol 42:703-706.

Lou HC (1991) Cerebral glucose metabolism in hyperactivity. N Engl J Med 324:1216-1217.

Lou HC, Henriksen L, Bruhn P, Borner H, Nielsen JB (1989) Striatal dysfunction in attention deficit and hyperkinetic disorder. Arch Neurol 46:48-52.

Mannuzza S, Klein RG, Bessler A, Malloy P, LaPadula M (1993) Adult outcome of hyperactive boys: educational achievement, occupational rank, and psychiatric status. Arch Gen Psychiatry 50:565-576.

Matochik JA, Liebenauer LL, King C, Szymanski HV, Cohen RM, Zametkin AJ (1994) Cerebral glucose metabolism in adults with attention deficit hyperactivity disorder after chronic stimulant treatment. Am J Psychiatry 151:658-664.

Matsui T, Hirano A (1978) An atlas of the human brain for computerized tomography. New York: Igaku-Shoin.

Matsumoto M, Hidaka K, Tada S, Tasaki Y, Yamaguchi T (1995) Fulllength cDNA cloning and distribution of human dopamine D4 receptor. Brain Res Mol Brain Res 29:157-162.

Mattes JA (1980) The role of frontal lobe dysfunction in childhood hyperkinesis. Compr Psychiatry 21:358-369.

McLellan C, Doudet D, Brucke T, Aigner T, Cohen R (1991) New rapid analysis method demonstrates differences in 6-[18-F]Fluoro-L-dopa plasma input curves with and without carbidopa in hemi-MPTP lesioned monkeys. Int J Rad Appl Instrum [A] 42:847-854.

Pycock CJ, Kerwin RW, Carter CJ (1980) Effect of lesion of cortical dopamine terminals on subcortical dopamine receptors in rats. Nature 286:74-76.

Reimherr FW, Wender PH, Ebert MH, Wood DR (1984) Cerebrospinal fluid homovanillic acid and 5-hydroxyindolacetic acid in adults with attention deficit hyperactivity disorder, residual type. Psychiatry Res 11:71-78.

Roth GS, Joseph JA (1994) Cellular and molecular mechanisms of impaired dopaminergic function during aging. Ann NY Acad Sci 719:129-135.

Schmidt U, Beyer C, Oestreicher AB, Reisert I, Schilling K (1996) Pilgrim C activation of dopaminergic D1 receptors promotes morphogenesis of developing striatal neurons. Neuroscience 74:453-460.

Seeman P, Bzowej NH, Guan HC, Bergeron C, Becker LE, Reynolds GP, Bird ED, Riederer P, Jellinger K, Watanabe S (1987) Human brain dopamine receptors in children and aging adults. Synapse 1:399-404.

Semple WE, Johnson JL, Cohen RM (1993) Reliability in positron emission tomography. In: Imaging drug action in the brain (London ED, ed), pp 297-316. Boca Raton, FL: CRC.

Shaywitz BA, Cohen DJ, Bowers MB (1977) CSF amine metabolites in children with minimal brain dysfunction: evidence for alteration of brain dopamine. J Pediatr 90:67-71.

Solanto MV (1998) Neuropsychopharmacological mechanisms of stimulant drug action in attention deficit/hyperactivity disorder: a review and integration. Behav Brain Res, in press.

Spencer T, Wilens T, Biederman J, Faraone SV, Ablon S, Lapey K (1995) A double-blind, cross-over comparison of methylphenidate and placebo in adults with childhood onset attention deficit hyperactivity disorder. Arch Gen Psychiatry 52:434-443.

Thompson TL, Moss RL (1997) Modulation of mesolimbic dopaminergic activity over the rat estrous cycle. Neurosci Lett 229:145-148.

Torstenson R, Hartvig P, Langstrom B, Westerberg G, Tedroff J (1997) Differential effects of levodopa on dopaminergic function in early and advanced Parkinson's disease. Ann Neurol 41:334-440.

Weiss G, Hechtman LT (1986) Hyperactive children grown up. New York: Guilford.

Wilens TE, Biederman J, Spencer TJ, Prince J (1995) Pharmacotherapy of adult attention deficit/hyperactivity disorder: a review. J Clin Psychopharmacol 15:270-279.

Woo TU, Pucak ML, Kye CH, Matus CV, Lewis DA (1997) Peripubertal refinement of the intrinsic and associational circuitry in monkey prefrontal cortex. Neuroscience 80:1149-1158.

Zametkin AJ, Nordahl TE, Gross M, King AC, Semple WE, Rumsey J, Hamburger S, Cohen RM (1990) Cerebral glucose metabolism in adults with hyperactivity of childhood onset. $\mathrm{N}$ Engl $\mathrm{J}$ Med 323:1361-1366.

Zametkin AJ, Liebenauer LL, Fitzgerald GA, King AC, Minkunas DV, Herscovitch P, Yamada EM, Cohen RM (1993) Brain metabolism in teenagers with attention deficit hyperactivity disorder. Arch Gen Psychiatry 50:333-340.

Zhu MY, Jurio AV, Paterson I, Boulton AA (1993) Regulation of striatal L-amino acid decarboxylase: effects of blockade or activation of dopamine receptors. Eur J Pharmacol 238:157-164. 